\title{
The War on Language: Providing Culturally Appropriate Care to Syrian Refugees
}

\author{
Meagan A. Roy, BSc, BHPE ${ }^{1}$ \\ ${ }^{1}$ Northern Ontario School of Medicine
}

A B STRACT

Ontario's Ministry of Health and Long-Term Care released a document in January 2016 regarding medical care of Syrian refugees as an effort to support primary care providers in the care and early assessment of their new patients [1]. The fourteen-page document provides an overview of the transition to Ontario medical care, from the Immigration Medical Examination prior to the refugee's entry into Canada, to health insurance coverage resources and information [1]. Health care providers may welcome this plethora of information, but the presence of a language barrier may prove to be the most considerable issue.

\section{RÉ S U MÉ}

En janvier 2016, le ministère de la Santé et des Soins de longue durée de l'Ontario a publié un document au sujet des soins médicaux pour les réfugiés syriens, pour appuyer les fournisseurs de soins primaires lorsqu'ils soignent et effectuent l'évaluation initiale de leurs nouveaux patients [1]. Le document de quatorze pages fournit un survol de la transition vers les soins de santé ontariens, allant de l'examen médical aux fins d'immigration précédant l'entrée du réfugié au Canada, à de l'information sur les régimes d'assurancemaladie [1]. Les professionnels de la santé recevront sans doute favorablement cette abondance d'information, mais la présence d'une barrière linguistique pourrait se révéler comme étant le problème le plus substantiel.

\section{INTRODUCTION}

By the end of February 2016, Canada is expected to have welcomed 25,000 Syrian refugees across the country [2]. Ontario's Health Minister, Eric Hoskins, has claimed that the province will resettle 10,000 refugees, with many in the Greater Toronto Area [3]. Furthermore, nearly 6,000 will end up in Quebec, according to Quebec's Immigration Minister, Kathleen Weil [3]. With over 9,000 Syrian refugees to relocate in six of the eight remaining provinces (British Columbia, Manitoba, Alberta, Nova Scotia, Saskatchewan, and New Brunswick, to date), it is reasonable to expect that many health care providers in Canada will have a part in ensuring the health of our newest residents [2].

The current clinical guidelines for immigrants and refugees come from an article published in the Canadian Medical Association Journal (CMAJ) in 2011 [4]. The comprehensive article relates to topics on infectious diseases, mental health and maltreatment, chronic and non-communicable diseases, and women's health [4]. In December 2015, an unedited article was posted on the CMAJ website in response, highlighting the need for a relevant and specific resource for health care providers treating Syrian refugees [5]. The government of Ontario has since provided such a resource, with references to both CMAJ articles, as well as the European Centre for Disease Prevention and Control (ECDC), in an effort to support primary care providers in the early assessment and care of Syrian refugees welcomed to their practice [1, 4-6]. These documents, comprising the CMAJ articles, the govKeywords: Language Barrier; Refugees ernment of Ontario package and ECDC resources, address many noteworthy topics, including post-traumatic stress disorder, contraception, and vision health, but unfortunately a lack of advice regarding transmission of information [1,4-6]. The issues stemming from a language barrier undoubtedly have a marked impact both on refugees, and health care providers who are unable to communicate with their new patients [7]. As such, the impact of the language barrier on consent and confidentiality, quality of care, and patient-physician relationship requires further discussion.

\section{THE EFFECTS OF THE LANGUAGE BARRIER}

The language barrier is a well-known issue in providing effective health care, and one that is especially relevant in the wake of welcoming the Syrian refugees [8]. Language barriers are experienced by both new and long-term immigrants due to difficulty in describing symptoms using the English language, as well as understanding English instructions from the physician [8]. These difficulties may cause delays in accessing health promotion programs, such as getting the flu shot [8], and can also lower odds of contacting a variety of health care providers, such as an optometrist $[7,9]$. Recent immigration contributes to a more pronounced reduction in Canadian immigrants initially accessing care due to communication difficulties, but language continues to be detrimental to health care delivery even after care is sought [9]. 


\section{Consent and Confidentiality}

Consent and confidentiality are everyday occurrences in medical practice. In the circumstances where consent is to be obtained and confidentiality to be kept, many health care professionals may fail to meet current ethical standards when a language barrier is present [7]. A study by Schenker et al. (2007) found that inpatients who do not speak English are less likely to have informed consent documented for invasive procedures such as lumbar puncture, thoracentesis, and paracentesis [10]. The use of a professional interpreter may not be enough to overcome this issue; many interpreters are not highly qualified and most physicians are not trained on how to effectively work with them [11]. Furthermore, interpreter services may be avoided altogether due to difficulties in accessibility and adequacy [12]. When services for interpretation are not readily available or are declined, family and friends of the patient, or ad hoc interpreters, are often used in the interim, leading to a breach in privacy and confidentiality [13]. The topic of interpreter services brings up more than consent and confidentiality issues, particularly regarding quality of care.

\section{Quality of Care}

A lack of proper interpretation services can mean reduced timeliness and quality of care for a patient [14]. While most hospitals and in-hospital specialists have access to translation services, an initial referral from a primary care provider is required [14]. However, most providers outside of the hospital do not commonly offer translation services [14]. People who have limited language proficiency may therefore be without access to specialists in the health care system, precluding early detection and treatment of disease [14].

Ethnic and linguistic diversity in the geographic location of the newly settled refugee or immigrant can have a strong influence on utilization of and access to health care providers in the area, especially when the refugee or immigrant has limited knowledge of the official languages [14]. A study by Wang and Kwak (2014) identified transnational care seeking in a number of South Korean immigrants in Toronto, Ontario. Study participants preferred to access Korean-speaking family physicians through transnational ties due to shorter wait times, personal health beliefs, treatment expectations, and the availability of health insurance and services [8]. Participants discussed the most significant problem being the long wait time for diagnosis, treatment, and operation in Canada versus same-day service offered in South Korea [8]. Expectations regarding health services were also an issue, revealing that MRI, ultrasound, and mammography were routine procedures performed for an annual medical examination in South Korea [8]. Considering these motivations, the addition of a language barrier could decrease the likelihood that these pa- tients would access English-speaking providers in Toronto $[8,14]$. The strategies used to overcome these issues ranged from receiving health information by phone or email from South Korea, importing medications from their home, or traveling to receive transnational medical care [8]. Some participants sought alternative care in Canada through practitioners of Chinese medicine, as they found it easier to communicate [8]. Cost remains an issue since these alternative practices, such as acupuncture, are not covered under the Ontario health plan [8]. Moreover, existing language barriers can further impact quality of care by stressing the relationship between the patient and provider.

\section{The Relationship Between the Patient and Provider}

Not only can language barriers affect overall quality of care, but there can also be a marked effect on the patient-provider relationship. Providers who do not speak the same language as the patient are viewed as less satisfactory, even when trained to work with, and accompanied by, a highly qualified interpreter $[7,11]$. Simply put, using a third party in the patient-provider interaction can have a negative impact [11]. Wang et al. (2008) found that study participants felt they could communicate more effectively with a provider who spoke the same language and have a better understanding of the diagnosis and instructions [14]. Perhaps the biggest gap in current practice is providing language access, despite knowing the effects of language barriers on immigrant and refugee health care.

\section{CURRENT SITUATION}

Part of addressing the problem with language barriers is being aware of their existence in the first place. However, the majority of working towards a solution comes from being proactive in the face of such an issue. There is an apparent absence of both motivation and resources to offer sufficient access to language services [11]. According to Gadon et al. (2006), physicians are aware of the need for language services, but little is being done about it [15]. The resource provided by the government of Ontario is available in both official languages of Canada. In an attempt to bridge the language barrier, a document translated to Arabic and two Kurdish dialects was released to provide information regarding health care options in Ontario for Syrian refugees [1]. However, the resources provided in the document are linked to websites that are only available in either English or French, and refugees are not provided with additional translated resources that are necessary for securing a family doctor or nurse practitioner [1]. While attempts are being made to address the language barrier, the question can be asked as to whether or not they are sufficient.

The healthy immigrant effect, an observed time where the health of immigrants is substantially higher than that of native-born in- 


\section{Commentary}

habitants, remains an observation generally in recent immigrants and refugees but can be lost in as little as two years after arriving to a new country $[16,17]$. It seems that the effects of language barriers are worsening, as most immigrants are coming from locations where the language is profoundly different from those spoken in Canada [16]. Recent health outcome disparities were found within immigrant subgroups, most notably in refugee communities [18]. The need to address current language barriers has been recognized by physicians, but overcoming them using costeffective strategies has proven difficult [15]. Recent cases have revealed the use of ad hoc interpretation instead of formal services due to cost effectiveness, availability, and the interpreter's understanding of the patient's culture [15]. Physicians in this same study voiced concern regarding the impact of language barriers on quality of care and patient safety, as well as an increased risk of malpractice [15]. As discussed, the most recent guidelines to support health care providers to practice in a culturally competent and appropriate way do not directly address language. Whether this is due to a lack of motivation, resources, or both, remains to be seen [11].

\section{MOVING FORWARD}

Perhaps the easiest piece of this puzzle is identifying the problems, but there are solutions that can be explored. The Purnell Model for Cultural Competence is a clinical assessment tool based on a multitude of theories and research, such as family development, psychology, anatomy, ecology, among many others (Figure 1) [19]. The model displays twelve domains that are related to and affected by each of the other domains, and has proven useful in planning strategies, developing assessment tools, and individualized interventions [19]. In fact, it has already been employed in the development of standards for the Oncology Nurses Society [19]. The model may also guide education strategies toward cultural practices, and administrative considerations in cultural issues among staff [19]. Research has also benefited from the model, assisting in conceptualizing research questions and the collection of demographic data [19]. Purnell's Guide to Culturally Competent Health Care was derived from the Purnell Model, and provides general and cultural specific knowl-

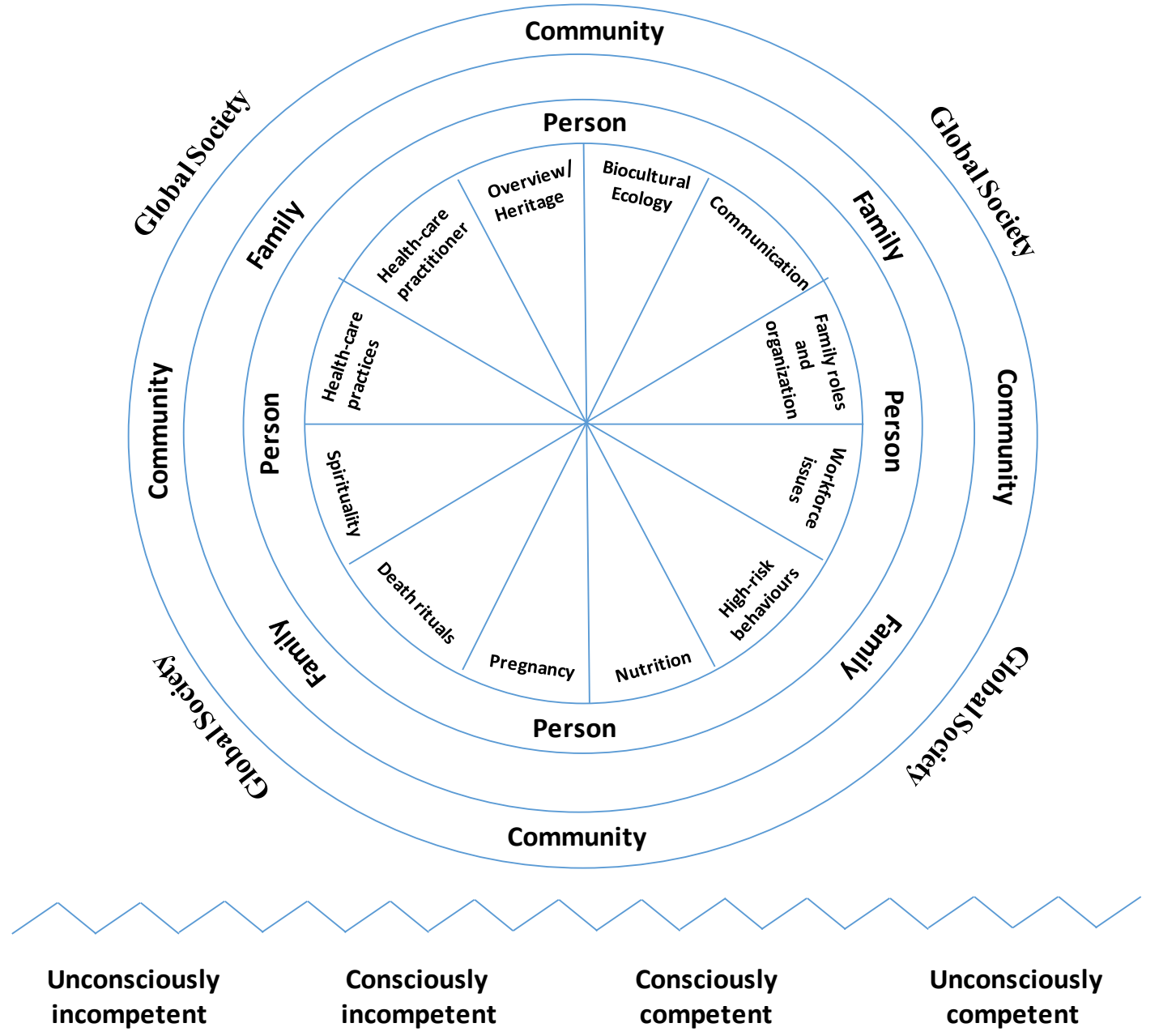

Figure 1: Purnell's Model for Cultural Competence [19]. 


\section{Considerations for Interacting with Non-Official Language Speaking Patients}

- Be alert to comments and behaviours from patients and family members that suggest they do not understand the provider.

- Create a system for interpretation.

- Compile a list of commonly used words in the dominant language of patients using the facility.

- Translate treatment plans and medication requirements into the languages of the patients who come to the facility.

- Translate pamphlets on common illnesses and diseases into the languages of the patients who come to the facility.

- Ensure that translated material is at grade 6 reading level.

Figure 2: Select considerations for the health care provider to contemplate when a language barrier is present in a clinical encounter, from Purnell's Guide to Culturally Competent Health Care [20].

edge to be contemplated by the health care provider [20]. Figure $\mathbf{2}$ contains select considerations for use when a language barrier is present in a clinical encounter [20].

Additional recommendations on education, research, and interpreter services, sampled from a comprehensive report published by Health Canada in 2001 to address language barriers in health care, may be considered as potential future steps [7]. Facilitating Canadian licensing procedures for international medical graduates is a consideration to increase the amount of health care providers who speak a non-official language [7]. Currently, recruitment initiatives exist to address local language barriers of First Nations populations geared toward Aboriginal undergraduate medical students [7]. However, no such programs traditionally exist for international medical graduates in Canada [7]. Additionally, research initiatives that focus on language access could be promoted to policymakers and health service planners [7]. Inclusion of language proficiency as a variable in analysis while promoting the inclusion of non-official language participants could assist in the development of service delivery models for interpreter services in communities and institutions [7]. Additional funding for community organizations offering newcomer services may increase outreach initiatives to provide referrals to appropriate health care providers, promote primary and preventive care, and enrol eligible immigrants into insurance plans [9]. Furthermore, strategies for both the training and accreditation of interpreters, as well as national standards of practice for interpreters, could be developed [7].

\section{CONCLUSION}

Language barriers in health care affect both patients and providers. The relationship between language proficiency and selfreported health is impactful not only for services surrounding health and society, but for medical curriculum and health information as well [21]. Language barriers have proven detrimental to consent and confidentiality issues, quality of care, and the overall patient-provider relationship. With the realization that a language barrier is a significant concern in health care access and delivery, it is time to put the numerous proposed solutions into action, and be proactive in addressing this issue directly.

\section{ACKNOWLEDGEMENTS}

Thank you to Dr. Larry Purnell for permission to use the Purnell Model for Cultural Competence.

\section{REFERENCES}

1. Ministry of Health and Long-Term Care [Internet]. Toronto (ON): Ministry of Health and Long-Term Care; 2016 Jan 21 [updated 2016 Jan 21; cited 2016 Feb 9]. Available from: http://www.health.gov.on.ca/en/pro/programs/ emb/syrianrefugees/docs/refugee_assessment_considerations.pdf.

2. Government of Canada [Internet]. Map of destination communities and service provider organizations. Government of Canada; 2015 Nov 9 [updated 2016 Feb 9; cited 2016 Feb 9]. Available from: http://www.cic.gc.ca/english/refugees/welcome/map.asp.

3. Woods A, Benzie R [Internet]. Ottawa (ON): Quebec, Ontario ready to accept 16,000 Syrian refugees, as Saskatchewan balks. Toronto Star; 2015 Nov 16 [updated 2015 Nov 16; cited 2016 Feb 9]. Available from: http://www. thestar.com/news/canada/2015/11/16/quebec-ontario-ready-to-accept16000-syrian-refugees-as-saskatchewan-balks.html.

4. Pottie K, Greenaway C, Feightner J, et al. Evidence-based clinical guidelines for immigrants and refugees. Can Med Assoc J. 2011;183(12):824-925

5. Pottie K, Greenaway C, Hassan G, Hui C, Kirmayer LJ [Internet]. Ottawa (ON): Caring for a newly arrived Syrian refugee family. Can Med Assoc J; 2015 Dec 8 [updated 201512 8; cited 2016 Feb 9]. Available from: http:// www.cmaj.ca/site/misc/caring-for-a-newly-arrived-syrian-refugee-familycmaj.151422.xhtml.

6. European Centre for Disease Prevention and Control [Internet]. Sweden: Infectious diseases of specific relevance to newly-arrived migrants in the EU/ EEA. 2015 Nov 19 [updated 2015 Nov 19; cited 2016 Feb 9]. Available from: http://ecdc.europa.eu/en/publications/Publications/Infectious-diseasesof-specific-relevance-to-newly-arrived-migrants-in-EU-EEA.pdf.

7. Health Canada [Internet]. Ottawa (ON): Language Barriers in Access to Health Care. 2001 Nov [published 2001 Nov; cited 2016 Feb 9]. Available from: http://www.hc-sc.gc.ca/hcs-sss/alt_formats/hpb-dgps/pdf/ pubs/2001-lang-acces/2001-lang-acces-eng.pdf.

8. Wang L, Kwak M-J. Immigration, barriers to healthcare and transnational ties: A case study of South Korean immigrants in Toronto, Canada. Soc Sci \& Med. 2014;133:340-348.

9. Lebrun LA. Effects of length of stay and language proficiency on health care experiences among Immigrants in Canada and the United States. Soc Sci \& 
Med. 2012; 74:1062-1072.

10. Schenker Y, Wang F, Selig SJ, et al. The impact of language barriers on documentation of informed consent at a hospital with on-site interpreter services. J Gen Intern Med. 2007;22(2):294-299.

11. Saha S, Fernandez A. Language barriers in health care. J Gen Intern Med. 2007;22(2):281-282.

12. Gerrish $\mathrm{K}$. The nature and effect of communication difficulties arising from interactions between district nurses and South Asian patients and their carers. Journal of Advanced Nursing. 2001;33(5):566-574.

13. Gerrish K, Chau R, Sobowale A et al. Bridging the language barrier: the use of interpreters in primary care nursing. Health and Social Care in the Community. 2004;12(55):407-413.

14. Wang L, Rosenberg M, Lo L. Ethnicity and utilization of family physicians: A case study of Mainland Chinese immigrant in Toronto, Canada. Soc Sci \& Med. 2008;67:1410-1422.

15. Gadon M, Balch GI, Jacobs EA. Caring for patients with limited English proficiency: The perspectives of small group practitioners. J Gen Intern Med. 2006;22[Suppl 2]:341-346.

16. Gushulak BD, Williams LS. National immigrant health policy: Existing policy, changing needs, and future directions. Can J Public Health. 2004;95(3):127129.

17. McDonald JT, Kennedy S. Insights into the 'healthy immigrant effect': health status and health service se of immigrants to Canada. Soc Sci \& Med. 2004;59(8):1613-1627.

18. DesMeules $\mathrm{M}$, Gold J, Kazanjian A et al. New approaches to immigrant health assessment. Can J Public Health. 2004;95(3):122-126

19. Purnell L. The Purnell Model for Cultural Competence. J of Trans Nursing. 2002;13(3):193-196.

20. Purnell LD. Guide to Culturally Competent Health Care. In: Chapter 3-Barriers to Culturally Competent Health Care. 3rd ed. Philadelphia, PA: F.A. Davis Company; 2014. 22-30 p.

21. Pottie K, Ng E, Spitzer D, et al. Language proficiency, gender and self-reported health. Can J Public Health. 2008;99(6):505-510. 